\title{
Surface wind energy trends near Taiwan in winter since 1871
}

\author{
Lei Zhang ${ }^{1,2,3}$, Tim $\mathrm{Li}^{1,4, *}$, and Mong-Ming $\mathrm{Lu}^{5}$ \\ ${ }^{I}$ Key Laboratory of Meteorological Disaster, Ministry of Education (KLME), Nanjing University of Information Science and \\ Technology, Nanjing, China \\ ${ }^{2}$ Joint International Research Laboratory of Climate and Environmental Change (ILCEC), Nanjing University of Information \\ Science and Technology, Nanjing, China \\ ${ }^{3}$ Collaborative Innovation Center on Forecast and Evaluation of Meteorological Disasters (CIC-FEMD), Nanjing University of \\ Information Science and Technology, Nanjing, China \\ ${ }^{4}$ Department of Atmospheric Sciences, University of Hawaii, Honolulu, HI, USA \\ ${ }^{5}$ Research and Development Center, Central Weather Bureau, Taipei City, Taiwan
}

\section{Article history:}

Received 27 December 2014

Revised 22 February 2016

Accepted 29 April 2016

Keywords:

Surface wind trend near Taiwan, SST

trend pattern, Global warming

\section{Citation:}

Zhang, L., T. Li, and M.-M. Lu, 2017: Surface wind energy trends near Taiwan in winter since 1871. Terr. Atmos. Ocean.

Sci., 28, 295-302, doi: 10.3319/

TAO.2016.04.29.01(A)

\begin{abstract}
The tropical surface wind speed in boreal winter reaches a maximum near Taiwan. This stable wind resource may be used for future clean energy development. How this surface wind energy source has changed in past 141 years is investigated using the $20^{\text {th }}$ century reanalysis dataset and CMIP5 models. Our observational analysis shows that the surface wind speed experienced a weakening trend in the past 141 years (1871 - 2010). The average decreasing rate is around $-1.4 \mathrm{~m} \mathrm{~s}^{-1}$ per century. The decrease is primarily attributed to the relative sea surface temperature (SST) cooling in the subtropical North Pacific, which forces a large-scale low-level anticyclonic circulation anomaly in situ and is thus responsible for the southerly trend near Taiwan. The relative SST trend pattern is attributed mainly to the greenhouse gas effect associated with anthropogenic activities. The southerly trend near Taiwan is more pronounced in the boreal winter than in summer. Such seasonal difference is attributed to the reversed seasonal mean wind, which promotes more efficient positive feedback in the boreal winter. The CMIP5 historical run analysis reveals that climate models capture less SST warming and large-scale anti-cyclonic circulation in the subtropical North Pacific, but the simulated weakening trend of the surface wind speed near Taiwan is too small.
\end{abstract}

\section{INTRODUCTION}

The surface wind near Taiwan in the boreal winter is characterized by pronounced northeasterlies as part of the Asian winter monsoon system ( $\mathrm{Li}$ et al. 2005). As revealed by the $20^{\text {th }}$ century reanalysis dataset, the wind in the region attains the highest wind speed in the tropical Pacific (Fig. 1a). Unlike the summer season when devastating typhoons frequently pass through the region, steady northeasterly trades in boreal winter may provide an uninterrupted clean energy source for millions of people living in the region. The natural questions are: did the wintertime surface wind speed change in the past 141 years? If yes, what caused the change?

Previous studies have shown that the dominant tropical Pacific interannual variability mode, i.e., El Niño and South-

\footnotetext{
* Corresponding author

E-mail:timli@hawaii.edu
}

ern Oscillation (ENSO), has substantial impact on the Asian monsoon system through a pronounced low-level Philippine Sea anticyclone (PSAC) during the El Niño event (Wang et al. 2003; Wu et al. 2009, 2010). The PSAC persists in winter and spring as a result of local air-sea interaction. To the east of PSAC, the anomalous northeasterlies enhance the mean state winds, and thus lead to greater surface latent heat release that subsequently lowers the sea surface temperature (SST). The negative SST anomalies induce local drying anomalies, which further excite an anti-cyclonic Rossby wave to its west that in turn reinforces the PSAC. These results suggest that the atmosphere-ocean coupling in the tropical Pacific plays an important role in tropospheric circulation changes in the Asia-western Pacific sector, where Taiwan is located.

One of the most important external climate system 


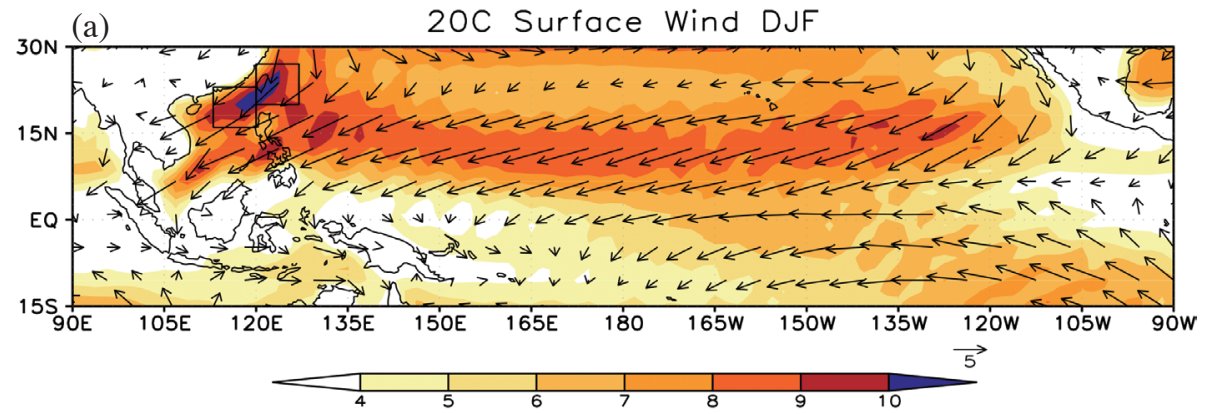

(b)

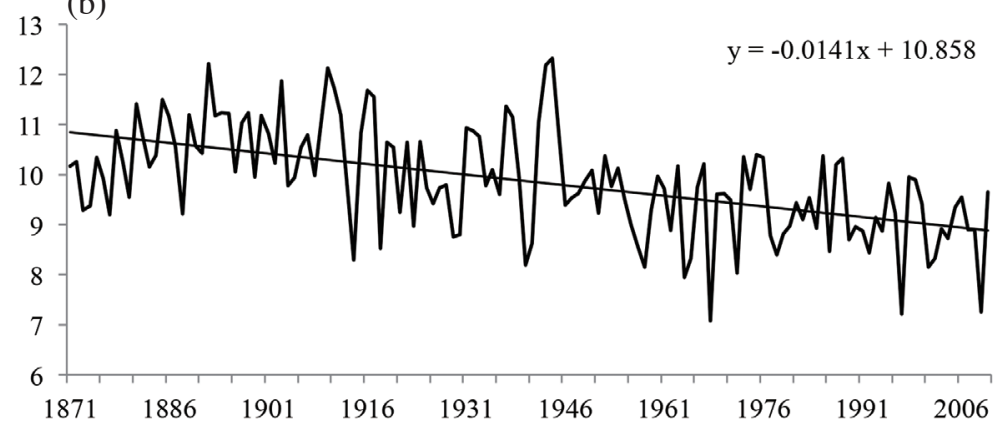

Fig. 1. (a) Climatological distribution of surface wind (vector) and surface wind speed (shading, units: $\mathrm{m} \mathrm{s}^{-1}$ ) in boreal winter. (b) Time series of area averaged [denoted by boxes in (a), $113-120^{\circ} \mathrm{E}$ and $16-23^{\circ} \mathrm{N} ; 120-127^{\circ} \mathrm{E}$ and $20-27^{\circ} \mathrm{N}$ ] surface wind speed near Taiwan and its linear trend.

forcing in the past decades is the emission of greenhouse gases (GHGs) associated with anthropogenic activities, which induces steady rising global mean surface temperature and substantial changes in the global climate system [IPCC AR5 report (IPCC 2013)]. Future projections from climate models also suggest that prominent changes will occur as a consequence of the GHG-effect, e.g., the global rainfall pattern is altered in a warmer climate. The location and frequency of tropical cyclone (TC) genesis and the occurrence of extreme events are influenced as well (e.g., Chou and Neelin 2004; Knutson et al. 2010; Li et al. 2010; Seager et al. 2010; Allan et al. 2014; Zhang et al. 2017). Is the long-term change in surface winds near Taiwan related to the large-scale circulation change in the global climate system in the past 141 years? If so, how does the global warming trend influence the surface wind speed near Taiwan? This study addresses these questions using both a 141-yr reanalysis product and projections from CMIP5 climate models.

\section{DATA AND MODELS}

The primary data used in this study are (1) monthly surface wind at $10 \mathrm{~m}$, sea level pressure (SLP), precipitation, surface air temperature at $2 \mathrm{~m}$, and surface latent heat flux fields from the $20^{\text {th }}$ century reanalysis dataset, which covers the period 1871 - 2011 (Compo et al. 2006, 2011); (2) monthly sea surface temperature (SST) dataset from Hadley center (Rayner et al. 2003); and (3) outputs from the historical simulations from the climate models that partici- pate in the coupled model intercomparison project phase 5 (CMIP5). The long-term linear trends in these variables in the past 141 years were calculated.

Twentieth century reanalysis and Hadley SST data are used for wind and SST trend analysis over the past 141 years (section 3). The CMIP5 historical runs from thirty-seven models are analyzed to evaluate the CMIP5 model performance in reproducing the observed surface wind changes near Taiwan (section 4). The five best models (Table 1) are selected based on whether they can reproduce the observed weakening surface wind speed trend near Taiwan and the large-scale circulation field and differential SST warming pattern trends in the subtropical North Pacific.

\section{SST AND WIND TREND PATTERNS IN PAST 141 YEARS}

Linear trend analysis shows that the surface wind speed in the boreal winter near Taiwan exhibits a steady weakening trend during the past 141 years (Fig. 1b). The wind decreasing rate is around $-1.4 \mathrm{~m} \mathrm{~s}^{-1}$ per century. This weakening trend is $95 \%$ statistically significant based on a t ratio test.

To understand the large-scale circulation feature associated with this trend we examined the linear precipitation, SLP, SST (with mean warming removed) and surface wind field trends in the boreal winter (December, January, and February, DJF). A large-scale low-level anti-cyclonic circulation trend shows up in the subtropical North Pacific 
Table 1. Five CMIP5 models that are used for analysis of surface wind trend near Taiwan.

\begin{tabular}{c|c|c}
\hline Model & Institute ID & Modeling center (Group) \\
\cline { 1 - 1 } GISS-E2-R & \multirow{2}{*}{ NASA GISS } & NASA Goddard Institute for Space Studies \\
\cline { 1 - 2 } GISS-E2-R-CC & & Met Office Hadley Center \\
\hline HadCM3 & MOHC & Institut Pierre-Simon Laplace \\
\hline IPSL-CM5A-MR & IPSL & Beijing Climate Center, China Meteorological Administration \\
\hline BCC-CSM-1.1-M & BCC &
\end{tabular}

(from $120^{\circ} \mathrm{E}-110^{\circ} \mathrm{W}$ and from $5-30^{\circ} \mathrm{N}$, Fig. 2c). Correspondingly, a positive SLP trend with a maximum center in the subtropical western Pacific occurs in the same latitudinal band (Fig. 2a). The anomalous anti-cyclone leads to southerly wind anomalies over the Taiwan region, which opposes the background northeasterlies and thus weakens the surface wind speed (Figs. 1 and 2c).

The occurrence of the large-scale low-level anti-cyclonic circulation trend is closely related to the differential SST warming trends in the subtropical region. As shown in Fig. 2c, SST warming is smaller in the subtropical North Pacific than in other regions. Such a differential warming pattern results in a positive SLP anomaly center in the region through air mass redistribution and eventually leads to a large-scale anti-cyclonic circulation anomaly. The overall precipitation, SLP, SST, and wind trend patterns are consistent with the observational study of Hung and Kao (2010). Shown in Figs. $2 \mathrm{~b}$ and $\mathrm{d}$ are the boreal summer trends. Similar to the wintertime changes, the relative SST trends compared to the domain averaged SST warming trend $\left(90^{\circ} \mathrm{E}-90^{\circ} \mathrm{W}\right.$ and $\left.30^{\circ} \mathrm{S}-60^{\circ} \mathrm{N}\right)$ are negative in the subtropical North Pacific in summer, which also leads to positive SLP trends and large-scale low-level anti-cyclonic circulation in situ (Figs. 2b and d).

What caused this SST differential warming trend in the past 141 years? As mentioned in the introduction, one of the most important external forcing that might contribute to the long-term climate system trend is the emission of GHGs associated with anthropogenic activities. It has been pointed out in previous studies that even though the GHG concentration distribution in the troposphere is relatively uniform, the simulated SST warming pattern is not (e.g., Zhang and Li 2014). One robust feature in the future projections from CMIP5 models is the relatively smaller SST warming in the subtropics compared to the tropical region (Xie et al. 2010; Zhang 2016), which is consistent with the SST trends in the past 141 years derived from the reconstructed data (Fig. 2c). The lesser warming in the subtropical region has been attributed to the evaporative damping mechanism associated with high surface wind speed in the subtropics (Liu et al. 2005; Xie et al. 2010; Zhang and Li 2014). Therefore, we attribute the formation of less SST warming in the subtropical North Pacific to the GHG effect, but other mechanisms, such as centennial variability's or other external forcing (i.e., aerosols) may also play a role. In addition to the evaporative damping mechanism, other processes, such as weakening of the Walker circulation under global warming, might also contribute to the formation of the differential SST warming pattern. As mentioned above, an anomalous large-scale anti-cyclonic circulation is induced in the subtropical North Pacific in response to the less warming trend, which weakens the surface wind speed over the Taiwan region in boreal winter.

Note also that over the western North Pacific (WNP) the local anti-cyclonic anomaly is clearly stronger in boreal winter compared to summer (Fig. 2), even though the relative SST trends in the subtropical North Pacific are similar in the two seasons. The weaker circulation anomaly during summer is consistent with the weaker positive SLP trends over WNP as well (Figs. 2a and b). Figure 3 shows the difference in the domain averaged meridional wind near Taiwan $\left(110-130^{\circ} \mathrm{E}, 15-30^{\circ} \mathrm{N}\right)$ between the periods $1871-1890$ and $1992-2011$. Southerly anomalies are found throughout the entire year, consistent with the anti-cyclonic circulation over WNP. Note that while the wintertime northerly wind is reduced, the summertime southerly is enhanced. This is because the mean meridional wind directions are opposite between winter and summer over the WNP region, whereas the anomalous wind blows toward the same direction throughout the year. Figure 3 also shows that the surface southerly difference in boreal winter is about two times as large as that in the boreal summer.

We argue that such a seasonal difference between wintertime and summertime southerly anomalies over the Taiwan region in Figs. 2 and 3 is attributed to the distinctive effect of positive feedback between the circulation and SST anomalies in the WNP region under different mean climate states in winter and summer. This is explained as follows: the smaller warming trend in subtropical North Pacific $\left(5-20^{\circ} \mathrm{N}\right.$, $\left.120-170^{\circ} \mathrm{E}\right)$ induces large-scale anomalous anti-cyclonic flow (Fig. 2c) in the region. During DJF, low-level northeasterly wind prevails over the tropical WNP, and therefore to the southeast of the WNP anti-cyclonic anomaly, anomalous northeasterlies reinforce the mean wind. As a result, the total wind speed is enhanced, which leads to greater latent heat fluxes released from the surface (Fig. 4a), and the cold 
SST anomalies are subsequently strengthened. The enhanced relatively cold SST anomalies reduce the precipitation in situ, which in turn forces the local low-level anomalous anticyclone to the west as a Rossby wave in response to the reduced diabatic heating (Gill 1980). This process eventually enhances the anti-cyclonic anomaly over WNP. To the northwest of the anti-cyclonic anomaly, the anomalous wind (southwesterly) is against the mean wind (northeasterly) so that the surface wind speed is reduced, which leads to less surface latent heat release (Fig. 4a) and higher SST (Fig. 2a). This long-term trend related positive feedback process is in a way similar to the ENSO-Asian monsoon teleconnection on
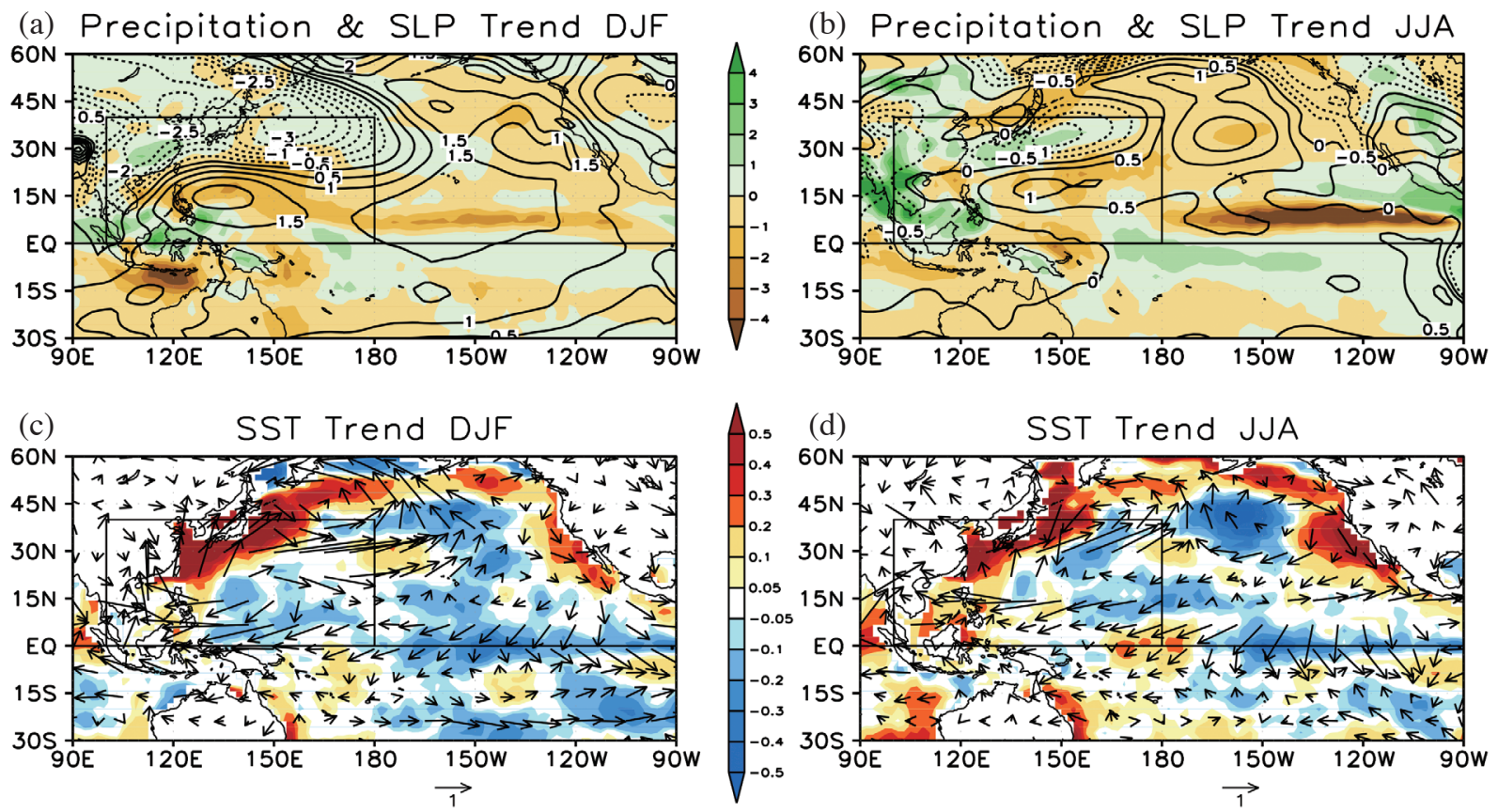

Fig. 2. Precipitation (shading, $m m$ day $^{-1}$ century $^{-1}$ ) and SLP (contour, $h P a$ century ${ }^{-1}$ ) trends during (a) boreal winter and (b) boreal summer in the past 141 years. Trends of SST (shading, $\mathrm{K}_{\text {century }}{ }^{-1}$, domain averaged warming over the region of $90^{\circ} \mathrm{E}-90^{\circ} \mathrm{W}$ and $30^{\circ} \mathrm{S}-60^{\circ} \mathrm{N}$ is removed) and surface wind field (units: $\mathrm{m} \mathrm{s}^{-1}$ ) in (c) boreal winter and (d) boreal summer.

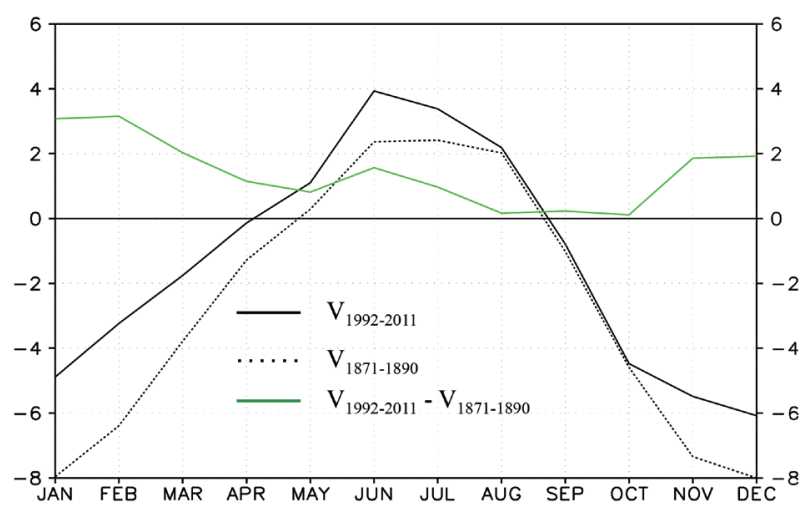

Fig. 3. Annual cycles of area averaged (denoted by boxes in Fig. $1 \mathrm{a}, 113-120^{\circ} \mathrm{E}$ and $16-23^{\circ} \mathrm{N} ; 120-127^{\circ} \mathrm{E}$ and $\left.20-27^{\circ} \mathrm{N}\right)$ meridional wind during 1871 - 1890 (dotted black line) and 1992 - 2011 (solid black line). The difference between the two curves is shown as solid green line (1992 - 2011 minus 1871 - 1890). Units: $\mathrm{m} \mathrm{s}^{-1}$. (Color online only) (a) Surface wind \& Latent Heat flux Trend DJF

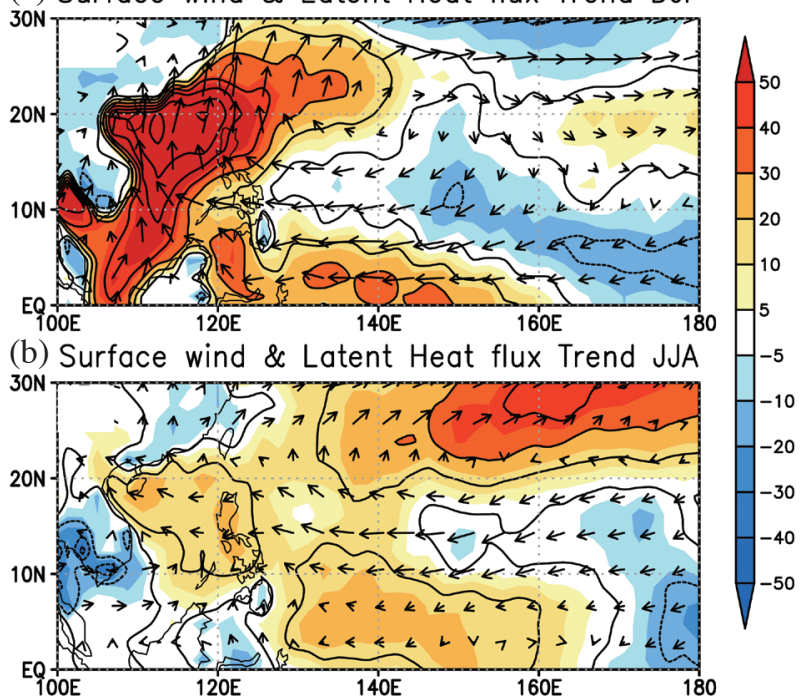

Fig. 4. The spatial linear surface latent heat flux pattern trends (shading, $\mathrm{W} \mathrm{m}^{-2}$ century $^{-1}$, positive denotes that ocean gains heat) and surface wind field (vector, $\mathrm{m} \mathrm{s}^{-1}$ century $^{-1}$ ) in (a) boreal winter and (b) boreal summer. Contour interval is $15 \mathrm{~W} \mathrm{~m}^{-2}$ century ${ }^{-1}$. 
the interannual timescale (Wang et al. 2003; Wu et al. 2009, 2010). The local air-sea interaction process may help sustain the east-west dipole-like SST anomaly and anti-cyclonic circulation over WNP in boreal winter (Figs. 2a and 4a). During the boreal summer, however, the mean flow direction reverses, and consequently, the northeasterly anomalies on the southeast flank of the anomalous anticyclone weakens the total wind speed. Hence, the positive SST-circulation feedback does not work in boreal summer (Fig. 4b). As a result, a much stronger east-west SST trend dipole and a low-level anti-cyclonic circulation pattern are observed in the boreal winter than in boreal summer (Figs. 2c and d), despite a similar relative SST warming trend in the subtropical North Pacific in the two seasons.

Figure 5 is another way of illustrating the seasonal dependence of the coupled SST-anti-cyclonic circulation trend pattern. It shows the east-west dipole seasonal evolution of the surface temperature trends (SST over ocean, surface air temperature over the land) and trend of the domain averaged low-level vorticity field over the WNP region. Consistent with Fig. 2, the negative vorticity (anti-cyclonic anomaly) and the east-west SST warming dipole in subtropical North Pacific persist throughout the entire year. It is also clear that the east-west SST anomaly dipole and the negative vorticity trend are much stronger during DJF, whereas such a dipole SST pattern and the WNP negative vorticity trend become much weaker in JJA. Such a seasonal difference clearly shows that the positive feedback that amplifies the local anti-cyclonic anomaly over the WNP through local air-sea interaction only works in the winter season.

\section{CHANGES IN SURFACE WIND ENERGY NEAR TAIWAN IN CMIP5 MODELS}

In the previous section, we demonstrated that the changes in surface wind speed near Taiwan are attributed primarily to the relative SST warming pattern, which might be associated with the GHG effect. In this section, CMIP5 models are analyzed to evaluate the climate models performance in reproducing the observed weakening trend in surface wind speed near Taiwan and the associated large-scale circulation trend pattern. There are historical simulations from thirtyseven CMIP5 models that are available for our analysis. We chose the five "best" models for further analysis (Table 1). The selected five models were chosen based on the following two criteria: (1) there are both a large-scale anti-cyclonic circulation anomaly and a relatively cold SST trend in the subtropical North Pacific; (2) the surface wind speed averaged in the two boxes near Taiwan (shown in Fig. 1a) has a negative trend.

Figure 6 shows the simulated low-level circulation, SLP and SST trend patterns in boreal winter in the historical runs from the five "best" models. Associated with a smaller SST trend in the subtropical North Pacific, a large-scale anti-cyclonic circulation trend shows up in situ. The anomalous anticyclone leads to a low-level southerly wind anomaly near Taiwan and thus weakened surface wind speed there in winter. These results are consistent with the observed features discussed in the previous section, although there are discrepancies in the anti-cyclonic circulation anomaly location among the models. Table 2 shows the domain averaged weakening trend of the surface wind speed near Taiwan (calculated based on the averaged wind speed within the two boxes shown in Fig. 1). Note that even though the selected "best" models capture the less SST warming and the large-scale anti-cyclonic circulation in the subtropical North Pacific, the surface wind speed weakening trends near Taiwan in the models (Table 2) are much smaller than the observed value ( $-1.4 \mathrm{~m} \mathrm{~s}^{-1}$ per century), and the east-west SST dipole structure in the WNP region is not as clear as that in the observation (Fig. 6).

\section{CONCLUSION}

Steady northeasterly trade winds provide stable surface wind energy over Taiwan during the boreal winter. The long-term surface wind speed trend near Taiwan in the DJF in the past 141 years is investigated using the $20^{\text {th }}$ century reanalysis and the observed SST data. It was found that there is a steady decreasing trend in surface wind speed near Taiwan in the boreal winter. The average decreasing rate is around $-1.4 \mathrm{~m} \mathrm{~s}^{-1}$ per century.

The cause of this weakening trend is attributed to the occurrence of a large-scale low-level anti-cyclonic circulation trend pattern in response to less SST warming in the subtropical North Pacific. It is further noted that although the relative SST trend pattern and anomalous large-scale anti-cyclonic flow appear in both the winter and summer seasons, such a circulation anomaly is much stronger during the boreal winter than during the boreal summer. This

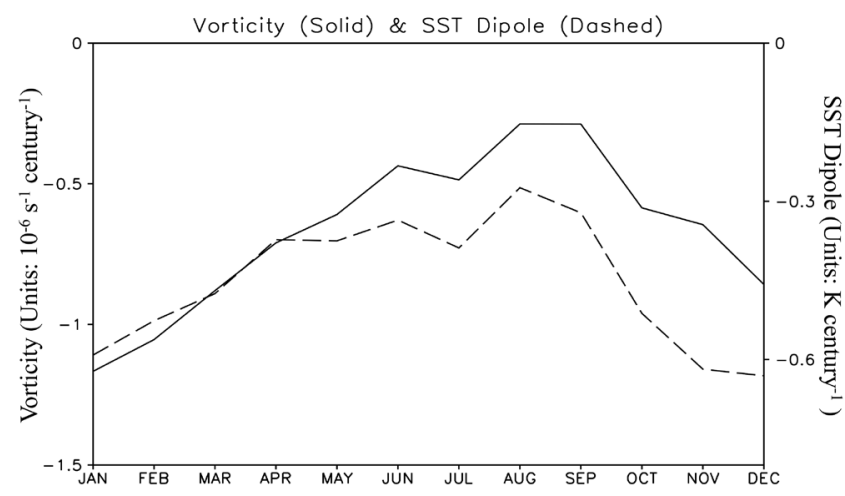

Fig. 5. Seasonal evolution of the east-west surface temperature dipole trends $\left(0-20^{\circ} \mathrm{N}, 135^{\circ} \mathrm{E}-180^{\circ}\right.$ minus $20-35^{\circ} \mathrm{N}, 120-145^{\circ} \mathrm{E}$, dashed line, $\mathrm{K}_{\text {century }}{ }^{-1}$, right axis) and the surface vorticity field averaged in the domain $5-35^{\circ} \mathrm{N}, 130^{\circ} \mathrm{E}-180^{\circ}$ (solid line, $10^{-6} \mathrm{~s}^{-1}$ century ${ }^{-1}$, left axis). 
Trends of SST (shading), SLP (contour) and surface wind in Historical runs
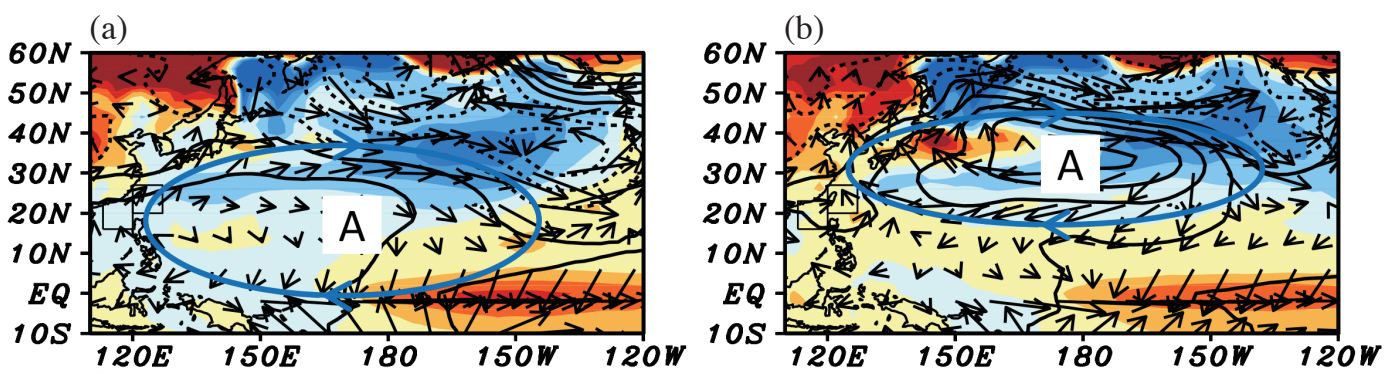

(c)

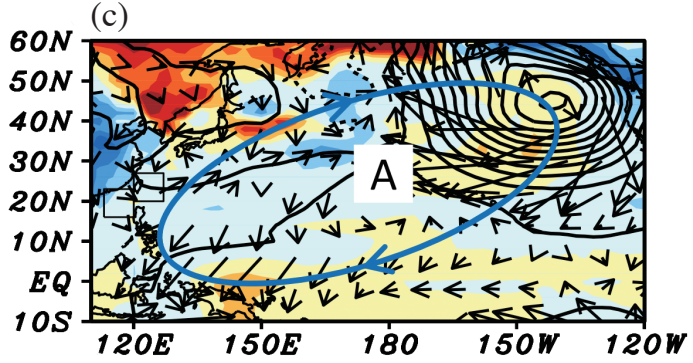

(d)

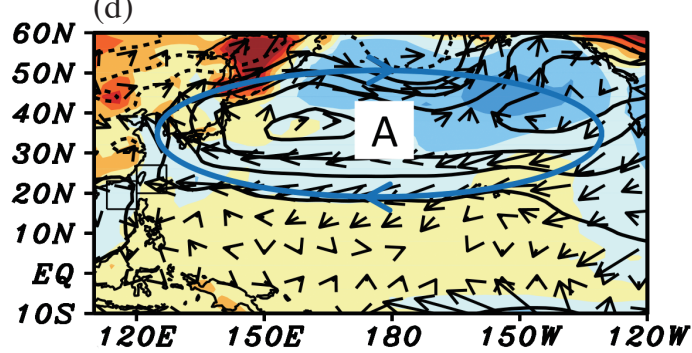

(e)

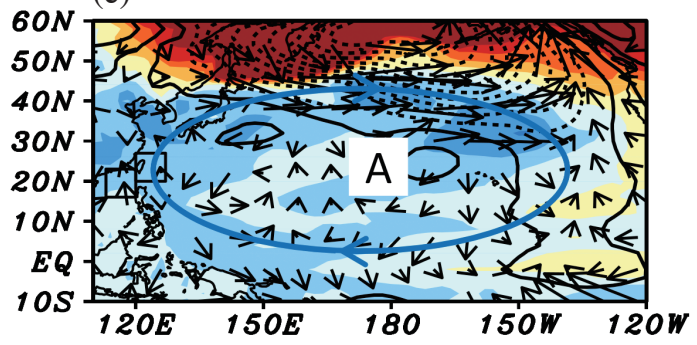

(f)

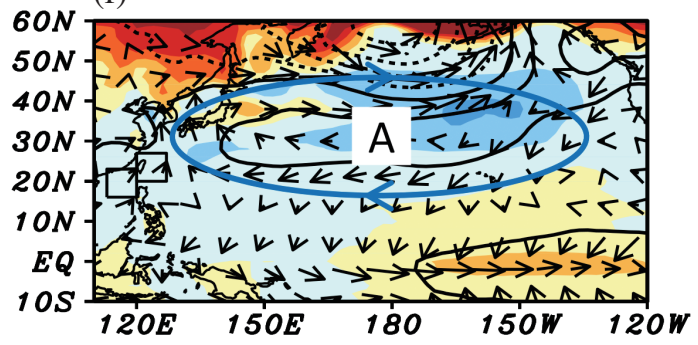

$$
\overrightarrow{0.5}
$$

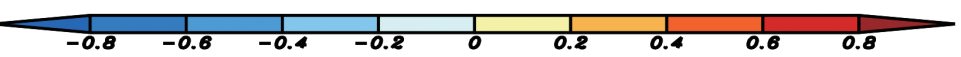

Fig. 6. Surface wind (vector, $\mathrm{m} \mathrm{s}^{-1}$ century $^{-1}$ ), SLP (contour, $0.3 \mathrm{hPa}$ century ${ }^{-1}$ interval), and surface temperature (shading, $\mathrm{K}$ century ${ }^{-1}$ ) trends during boreal winter in the historical runs from (a) GISS-E2-R-CC, (b) GISS-E2-R, (c) HadCM3, (d) IPSL-CM5A-MR, and (e) bcc-csm-1-1-m. (f) The ensemble mean results from the five models above. The Blue circles denote the large-scale anti-cyclonic circulation anomalies and the letter "A" stands for anticyclone.

Table 2. Area averaged surface wind speed trends near Taiwan in CMIP5 historical runs (domain shown in Fig. 1, units: $\mathrm{m} \mathrm{s}^{-1}$ century ${ }^{-1}$ ).

\begin{tabular}{c|c}
\hline Model & Surface wind speed \\
\hline GISS-E2-R-CC & -0.257997 \\
\hline GISS-E2-R & -0.135871 \\
\hline HadCM3 & -0.132459 \\
\hline IPSL-CM5A-MR & -0.0198252 \\
\hline bcc-csm-1-1-m & -0.0724054 \\
\hline Ensemble Mean & -0.124254 \\
\hline
\end{tabular}


is because the positive air-sea feedback associated with the mean state wind in the tropical WNP amplifies the local anti-cyclonic circulation anomaly and this effect works only in the boreal winter.

The formation of differential SST warming trend (less warming in subtropical North Pacific) may be primarily attributed to the GHG forcing and a longwave-evaporative damping mechanism (Liu et al. 2005; Xie et al. 2010; Zhang and $\mathrm{Li} 2014$ ) associated with the relatively high mean wind speed and mean evaporation in the subtropical region. Thus, the downward surface wind speed trend near Taiwan is ultimately linked to the climate mean state condition. Other mechanisms may also play a role in the formation of the relative SST warming pattern.

Changes in the surface wind speed near Taiwan in the historical runs from CMIP5 models were also analyzed. The five "best" models were chosen, in which the less SST warming and the large-scale anti-cyclonic circulation in the subtropical North Pacific are reproduced. It was found that the weakening surface wind speed trends near Taiwan in the models were too small compared to the observations. Hence further improvement of the climate models and better understanding of the Earth climate system responses to the GHG effect are still needed.

Acknowledgements This study is sponsored by China National 973 Program 2015CB453200, CWB Climate Project, NSFC grant 41475084, and ONR grant N00014-1210450. Support for the Twentieth Century Reanalysis Project dataset is provided by the U.S. Department of Energy, Office of Science Innovative and Novel Computational Impact on Theory and Experiment (DOE INCITE) program, Office of Biological and Environmental Research (BER), and the National Oceanic and Atmospheric Administration Climate Program Office. The International Pacific Research Center is partially sponsored by the Japan Agency for Marine-Earth Science and Technology (JAMSTEC). This is SOEST contribution number 9629, IPRC contribution number 1192 and ESMC contribution number 108.

\section{REFERENCES}

Allan, R. P., C. Liu, M. Zahn, D. A. Lavers, E. Koukouvagias, and A. Bodas-Salcedo, 2014: Physically consistent responses of the global atmospheric hydrological cycle in models and observations. Surv. Geophys., 35, 533-552, doi: 10.1007/s10712-012-9213-z. [Link]

Chou, C. and J. D. Neelin, 2004: Mechanisms of global warming impacts on regional tropical precipitation. $J$. Climate, 17, 2688-2701, doi: 10.1175/1520-0442(200 4) $017<2688: M O G W I O>2.0 . C O ; 2$. [Link]

Compo, G. P., J. S. Whitaker, and P. D. Sardeshmukh, 2006: Feasibility of a 100-year reanalysis using only surface pressure data. Bull.Amer. Meteorol.Soc., 87, 175-190, doi: 10.1175/BAMS-87-2-175. [Link]

Compo, G. P., J. S. Whitaker, P. D. Sardeshmukh, N. Matsui, R. J. Allan, X. Yin, B. E. Gleason, R. S. Vose, G. Rutledge, P. Bessemoulin, S. Brönnimann, M. Brunet, R. I. Crouthamel, A. N. Grant, P. Y. Groisman, P. D. Jones, M. C. Kruk, A. C. Kruger, G. J. Marshall, M. Maugeri, H. Y. Mok, Ø. Nordli, T. F. Ross, R. M. Trigo, X. L. Wang, S. D. Woodruff, and S. J. Worley, 2011: The twentieth century reanalysis project. Q.J.R. Meteorol.Soc., 137, 1-28, doi: 10.1002/qj.776. [Link]

Gill, A. E., 1980: Some simple solutions for heat-induced tropical circulation. Q. J. R. Meteorol. Soc., 106, 447462, doi: 10.1002/qj.49710644905. [Link]

Hung, C. W. and P. K. Kao, 2010: Weakening of the winter monsoon and abrupt increase of winter rainfalls over northern Taiwan and southern China in the early 1980s. J. Climate, 23, 2357-2367, doi: 10.1175/2009JCLI3182.1. [Link]

IPCC, 2013: Climate Change 2013: The Physical Science Basis, Cambridge University Press, Cambridge, United Kingdom and New York, NY, USA, 1535 pp.

Knutson, T. R., J. L. McBride, J. Chan, K. Emanuel, G. Holland, C. Landsea, I. Held, J. P. Kossin, A. K. Srivastava, and M. Sugi, 2010: Tropical cyclones and climate change. Nat. Geosci., 3, 157-163, doi: 10.1038/ ngeo779. [Link]

Li, T., Y. C. Tung, and J. W. Hwu, 2005: Remote and local SST forcing in shaping Asian-Australian monsoon anomalies. J. Meteorol. Soc. Jpn., 83, 153-167, doi: 10.2151/jmsj.83.153. [Link]

Li, T., M. Kwon, M. Zhao, J. S. Kug, J. J. Luo, and W. Yu, 2010: Global warming shifts Pacific tropical cyclone location. Geophys. Res. Lett., 37, L21804, doi: 10.1029/2010GL045124. [Link]

Liu, Z., S. Vavrus, F. He, N. Wen, and Y. Zhong, 2005: Rethinking tropical ocean response to Global warming: The enhanced equatorial warming. J. Climate, 18, 4684-4700, doi: 10.1175/JCLI3579.1. [Link]

Rayner, N. A., D. E. Parker, E. B. Horton, C. K. Folland, L. V. Alexander, D. P. Rowell, E. C. Kent, and A. Kaplan, 2003: Global analyses of sea surface temperature, sea ice, and night marine air temperature since the late nineteenth century. J. Geophys. Res., 108, doi: 10.1029/2002JD002670. [Link]

Seager, R., N. Naik, and G. A. Vecchi, 2010: Thermodynamic and dynamic mechanisms for large-scale changes in the hydrological cycle in response to global warming. J. Climate., 23, 4651-4668, doi: 10.1175/2010JCLI3655.1. [Link]

Wang, B., R. Wu, and T. Li, 2003: Atmosphere-warm ocean interaction and its impacts on Asian-Australian monsoon variation. J.Climate., 16, 1195-1211, doi: 10.1175 /1520-0442(2003)16<1195:AOIAII>2.0.CO;2. [Link]

Wu, B., T. Zhou, and T. Li, 2009: Seasonally evolving 
dominant interannual variability modes of East Asian climate. J. Climate, 22, 2992-3005, doi: 10.1175/2008JCLI2710.1. [Link]

Wu, B., T. Li, and T. Zhou, 2010: Relative contributions of the Indian Ocean and local SST anomalies to the maintenance of the western North Pacific anomalous anticyclone during the El Niño decaying summer. J. Climate, 23, 2974-2986, doi: 10.1175/2010JCLI3300.1. [Link]

Xie, S. P., C. Deser, G. A. Vecchi, J. Ma, H. Teng, and A. T. Wittenberg, 2010: Global warming pattern formation: Sea surface temperature and rainfall. J. Climate, 23, 966-986, doi: 10.1175/2009JCLI3329.1. [Link]
Zhang, L., 2016: The roles of external forcing and natural variability in global warming hiatuses. Clim. Dyn., 47, 3157-3169, doi: 10.1007/s00382-016-3018-6. [Link]

Zhang, L. and T. Li, 2014: A simple analytical model for understanding the formation of sea surface temperature patterns under global warming. J. Climate, 27, 84138421, doi: 10.1175/JCLI-D-14-00346.1. [Link]

Zhang, L., K. B. Karnauskas, J. P. Donnelly, and K. Emanuel, 2017: Response of the North Pacific tropical cyclone climatology to global warming: Application of dynamical downscaling to CMIP5 models. J. Climate, 30, 1233-1243, doi: 10.1175/jcli-d-16-0496.1. [Link] 